Check for updates

Cite this: RSC Adv., 2019, 9, 34076

Received 24th June 2019

Accepted 18th October 2019

DOI: 10.1039/c9ra04729h

rsc.li/rsc-advances

\title{
Fabrication of a cost-effective lemongrass (Cymbopogon citratus) membrane with antibacterial activity for dye removal
}

\author{
Zengxiao Cai, Rechana Remadevi, Md Abdullah Al Faruque, Mohan Setty, Linpeng Fan, \\ Abu Naser Md Ahsanul Haque and Maryam Naebe (D)*
}

\begin{abstract}
Dye wastewater has attracted much attention due to its severe environmental and health problems. The main challenge of separating dyes from wastewater, using adsorption, is developing a functional adsorbent that is cost-effective and sustainable. In this work, we have fabricated a novel low-cost membrane with antibacterial properties from naturally sustainable lemongrass (LG). Lemongrass was cut and milled into powder, then dissolved to prepare a lemongrass membrane. Graphene oxide (GO) was also included to prepare a LG/GO composite membrane. The physiochemical and antibacterial properties of membranes were evaluated and their dye adsorption capability was examined using methylene blue (MB) dye at different concentrations. The kinetic study revealed that the MB adsorption process complied with the pseudo second-order model. The lemongrass membrane showed a rough surface morphology, high reduced modulus and hardness, yet comparable dye adsorption to the LG/GO composite membrane. Considering the natural sustainability of lemongrass as an abundant cellulosic resource, its excellent dye adsorption, antibacterial properties and low cost as well as the facile fabrication technology, the lemongrass membrane could be a promising candidate for dye removal from wastewater with easy separation after use.
\end{abstract}

\section{Introduction}

With the fast development of industrialization, water resources have been seriously contaminated. In the textile industrial sector alone, approximately 200000 tons of dye are discharged in effluent each year, which is attributed to the low efficiency of the dyeing process. ${ }^{1} \mathrm{~A}$ large quantity of water has been used by the textile industry during the dyeing and finishing process. Due to the substantial amount of wastewater and the complicated composition, the effluent from textile plants has been regarded as the greatest source of water pollution. ${ }^{2}$ Hence, the dye removal and reusability of the dyed water has attracted much attention.

Due to the large quantity, high toxicity and complex composition, dye wastewater induces not only environmental pollution but also health hazards. ${ }^{3}$ Currently, different methods such as chemical coagulation, electrolysis, oxidation and adsorption have been used to treat wastewater. ${ }^{4-6}$ However, most of these techniques are limited by their high cost, low adsorption capacity or secondary environmental pollution due to the large quantity of wastewater. The adsorption treatment has been widely used for dye-waste removal because of its simplicity, high efficiency and multifunction. ${ }^{7,8}$ However, it is

Deakin University, Institute for Frontier Materials, Geelong, Victoria 3216, Australia. E-mail: maryam.naebe@deakin.edu.au still challenging to fabricate a cost-effective environmentally friendly and sustainable adsorbent for dye removal. In addition to the dyes, microorganisms in polluted water can cause biofouling and degradation of metal surfaces which influence industry applications. ${ }^{9}$ Therefore, it would be beneficial to have dye adsorbent with an antibacterial property.

Although graphene oxide (GO) with a large surface area has demonstrated a high dye adsorption capability and antibacterial property, ${ }^{10,11}$ the high cost, 2D structure and difficulty of separation after adsorption limit the application of GO in dye adsorption. To solve these problems GO and natural materials have been made into nanocomposites, which have shown a promising application in dye removal. ${ }^{12,13}$ Natural materials as adsorbent ${ }^{14-16}$ have attracted more attention because of their low cost, non-toxicity, biodegradability and sustainability.

Lemongrass (LG) is lignocellulose biomass containing around $40 \%$ cellulose and approximately $23 \%$ hemicellulose. ${ }^{17}$ Lemongrass, with good biological properties such as antimicrobial, anti-fungal, anti-inflammatory, antioxidant, etc., has been widely used in therapies, cosmetics, food preservation and agriculture. ${ }^{17,18}$ Due to the good adsorbent characteristics of cellulosic materials, ${ }^{15,16}$ lemongrass can be a promising candidate for dye adsorption. Additionally the good antibacterial and antifungal properties of lemongrass may further enhance its application in dye adsorption. Previous studies have demonstrated various forms of lemongrass such as powder, ash and 
extracted oil residual can absorb different metal ions and dye from the aqueous solutions. ${ }^{\mathbf{1 7 , 1 9 , 2 0}}$ Only one paper regarding lemongrass dye adsorption has reported that the lemongrass ash is an efficient adsorbent for the adsorption of methylene blue from wastewater. ${ }^{20}$ However, there is a difficulty of separating ash from the water after dye adsorption. In this study, lemongrass was fabricated into membranes as dye absorbent to study their dye adsorption properties and resolve the separation problem of lemongrass powder or ash.

To the best of our knowledge, there are very few, if any, reports on fabrication of membrane from lemongrass. Therefore, the objective of this study has been to understand the physiochemical and antibacterial properties as well as adsorption kinetics of membranes fabricated from lemongrass. In order to achieve this, we have: (a) fabricated lemongrass membrane and LG/GO composite membrane where separation of membrane from solution is much easier than powder or ash absorbents; and (b) examined the impact of membrane structure on dye adsorption capability of the composite membranes using methylene blue with the aim of rationalising the relationship between the morphology, surface, dye adsorption and mechanical properties. Antibacterial properties of the membranes were also studied to investigate if the fabrication process would retain the natural properties of lemongrass. The finding may assist the fabrication of cost-effective dye adsorbent membrane from natural lemongrass with antibacterial properties.

\section{Results and discussion}

\section{Particle size measurement}

The particle size distribution of lemongrass snippets (LGSNP) and spray dried powder (LGSDP) are shown in Fig. 1. Table 1 demonstrates the particle size of $d(0.1), d(0.5)$ and $d(0.9)$ at snippets phase and powder phase. While the snippets were converted into spray-dried powder, the particle size distribution changed significantly. The particle size of $d$ (0.5) of LGSNP decreased from $544.34 \mu \mathrm{m}$ to $7.63 \mu \mathrm{m}$ while converted into LGSDP. A similar reduction in the particle size was found in case of $d(0.1)$ and $d(0.9)$ during the formation of LGSDP from

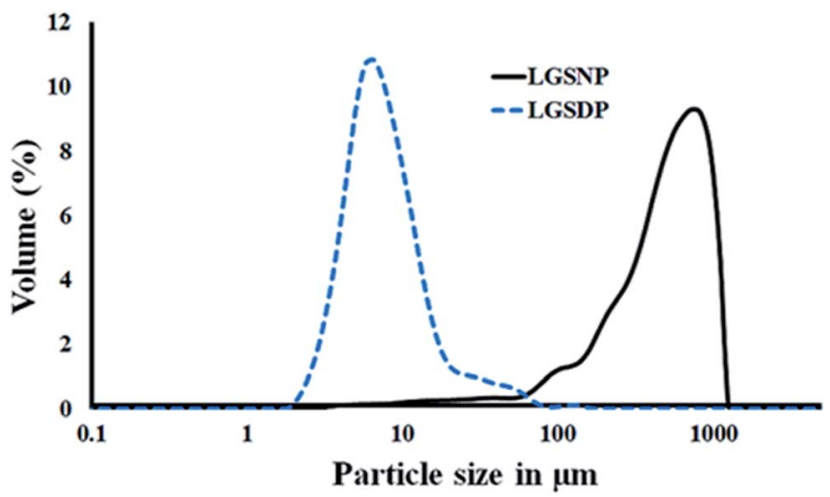

Fig. 1 Volume-based particle size distribution of lemongrass snippets (LGSNP) and spray dried powder (LGSDP).
Table 1 The distribution of snippets and spray dry powder of lemongrass

\begin{tabular}{lccc}
\hline Sample name & $d(0.1)(\mu \mathrm{m})$ & $d(0.5)(\mu \mathrm{m})$ & $d(0.9)(\mu \mathrm{m})$ \\
\hline Lemongrass snippets & 133.57 & 544.34 & 1009.65 \\
Lemongrass spray dry & 4.20 & 7.63 & 17.87 \\
powder & & &
\end{tabular}

LGSNP. This depletion of particle size might be due to the intermediate attritor milling process which has been performed before the conversion of LGSNP to LGSDP. ${ }^{21}$ The attritor mill vessel contains impellers and ceramic balls which rotate at $280 \mathrm{rpm}$ during milling. Hence, the breakdown of the particle size is attributed to the impellers and ceramic balls. It has already been reported that the lower the particle size, the easier the dissolution process. ${ }^{22}$ Therefore, in this work, to accelerate the dissolution process and to fabricate a uniform membrane the lemongrass spray-dried powder (LGSDP) were selected.

\section{Morphology and structure of the membrane}

The surface and cross-section morphology of the prepared membranes are shown in Fig. 2. Cross sections are presented on top right side of images. The LGES membrane showed a relatively smooth surface with many holes on the surface which could be formed due to the local contract of the membrane during the drying time of membrane fabrication. The crosssection image (Fig. 2a) showed a compressed and smooth structure. Fig. 2b shows both rough surface and cross-section morphology of the LGDM membrane, where the small particles induced the roughness due to the controlled dissolution of LG. GO was dispersed uniformly in the membrane as shown in Fig. 2c and d. The cross-section image (Fig. 2a) showed a compressed and smooth structure. Fig. $2 \mathrm{~b}$ shows both rough surface and cross-section morphology of the LGDM membrane, where the small particles induced the roughness due to the

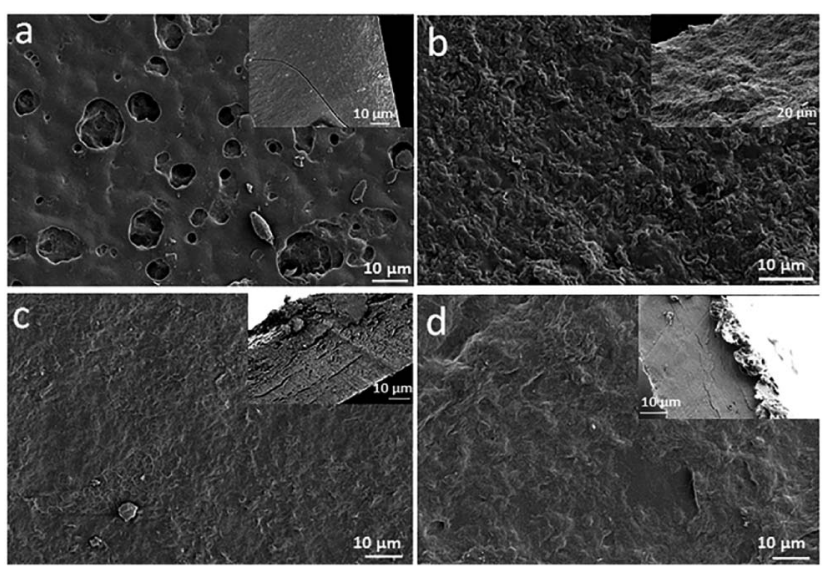

Fig. 2 Surface morphology and cross-section images (inset) of lemongrass membranes. (a) LGES (lemongrass extracted solution); (b) LGDM (lemongrass dissolved mixture); (c) LGES/GO (LGES mixed with graphene oxide); (d) LGDM/GO (LGDM mixed with graphene oxide). 
controlled dissolution of LG. GO was dispersed uniformly in the membrane as shown in Fig. $2 c$ and d. The surface of LGES/GO and LGDM/GO membranes (Fig. 2c and d) were rougher compared to their pure corresponding LGES and LGDM membrane without GO. However, LGES/GO showed a smoother surface than that of LGDM. While cross-section images of both LGES/GO and LGDM/GO membranes showed layered structure, some cracks were also observed, which could be attributed to the arrangement of GO layer in the formation of membrane. The results were found to agree with the previous studies, where layered structure in cellulose/graphene nanocomposite paper ${ }^{23}$ and cellulose/graphene/graphene oxide membrane ${ }^{24}$ were reported.

\section{FTIR and XRD analysis}

Fig. 3a shows the FTIR spectra of lemongrass/GO composite membranes. The peaks at $3305 \mathrm{~cm}^{-1}$ (LGES) and $3296 \mathrm{~cm}^{-1}$ (LGDM) corresponded to the stretching vibration of the hydroxyl $(-\mathrm{OH})$ group. However, there was a shift in the intensity of hydroxyl group in the composite membranes of LGES/GO $\left(3340 \mathrm{~cm}^{-1}\right)$ and LGDM/GO $\left(3344 \mathrm{~cm}^{-1}\right)$ which was attributed to the strong absorption of hydroxyl of GO. ${ }^{25}$ The peaks at $2918 \mathrm{~cm}^{-1}$ (LGES, LGDM, LGDM/GO), and $2922 \mathrm{~cm}^{-1}$ (LGES/ GO) were associated to the stretching vibration of the alkane (C-H) group owing to the methyl and methylene group of cellulose. ${ }^{26}$ The peak intensity at $1718 \mathrm{~cm}^{-1}$ corresponding to the $\mathrm{C}=\mathrm{O}$ stretching vibration of $-\mathrm{COOH}$ group of $\mathrm{GO}$ quite weak in LGES/GO and LGDM/GO composite membrane, which indicated the successful formation of hydrogen bonds with the -OH groups of LGES and LGDM in the composite membrane. ${ }^{26}$ The peaks at $1635 \mathrm{~cm}^{-1}$ (LGES), $1637 \mathrm{~cm}^{-1}$ (LGDM), $1633 \mathrm{~cm}^{-1}$ (LGES/GO) and $1641 \mathrm{~cm}^{-1}$ (LGDM/GO) were assigned to the $\mathrm{C}=\mathrm{C}$ stretching. The peak at $1410 \mathrm{~cm}^{-1}$ (LGES) and $1417 \mathrm{~cm}^{-1}$ (LGDM) shifted to $1420 \mathrm{~cm}^{-1}$ (LGES/GO) and $1421 \mathrm{~cm}^{-1}$ (LGDM/GO), which indicated the existence of GO in the composite membrane. The peaks at $1031 \mathrm{~cm}^{-1}$ (LGES), $1037 \mathrm{~cm}^{-1}$ (LGDM), $1035 \mathrm{~cm}^{-1}$ (LGES/GO) and $1026 \mathrm{~cm}^{-1}$ (LGDM/GO) were assigned to the $\mathrm{C}-\mathrm{O}$ stretching. The peaks of the FTIR spectra of LGES/GO and LGDM/GO presented a combination of peaks of pure GO, LGES and LGDM, which indicated the successful dispersion of GO in the nanocomposites. The results are in agreement with morphology
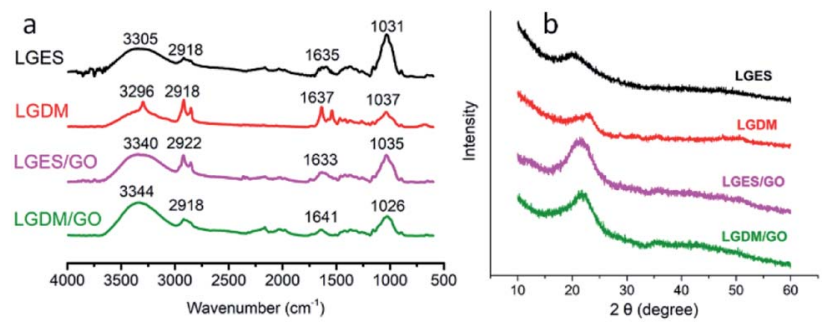

Fig. 3 FTIR spectra (a) and XRD patterns (b) of LGES (lemongrass extracted solution) membrane, LGDM (lemongrass dissolved mixture) membrane, LGES/GO (LGES mixed with graphene oxide) membrane and LGDM/GO (LGDM mixed with graphene oxide) membrane. analysis that showed the uniform dispersion of GO in the membrane (Fig. 2c and d).

XRD patterns of all membranes are shown in Fig. $3 \mathrm{~b}$. The characteristic peaks at $20.6^{\circ}$ (LGES), 23.2 (LGDM), $20.8^{\circ}$ (LGES/ GO) and $21.4^{\circ}$ (LGDM/GO) corresponded to the cellulose. ${ }^{27}$ The $2 \theta$ peak of GO at $12.0^{\circ}$ was not observed in the GO/LG composite membranes. In agreement with study of Han et al. on regenerated cellulose/graphite oxide (GO) blended films, ${ }^{28}$ the disappearance of the corresponding GO peak might be due to further GO exfoliation into single layer as a result of mixing process. Additionally, it has been reported that the hydrogen bond interactions between cellulose and GO induced the disappearance of the periodic interlayer spacing. ${ }^{29}$ This interaction has been supported by FTIR, where a shift in the intensity of the hydroxyl group in the composite membranes was observed.

\section{Nano-indentation}

Fig. 4a shows hardness results of all fabricated membranes. LGDM membrane showed higher hardness (329.5 $\pm 16.4 \mathrm{MPa})$ than LGES membrane $(222.2 \pm 11.9 \mathrm{MPa})$. The mixture of the dissolved and undissolved particle as well as the compacted structure (Fig. 2b) may have contributed to the higher hardness of LGDM compared to LGES membrane. With the addition of GO to LGES, hardness increased by $5 \%$, from $222.2 \pm 11.9 \mathrm{MPa}$ (LGES) to $232.9 \pm 23.2 \mathrm{MPa}$ (LGES/GO). Since GO possess good mechanical properties, it was not surprising that addition of GO enhanced the hardness of the membrane, although it resulted in formation of cracks as shown by SEM cross-section image. Surprisingly, LGDM membrane showed the highest hardness, which was higher than that of the LGDM/GO membrane (176.9 $\pm 10.4 \mathrm{MPa}$ ). This might be due to the fact that the addition of GO destroyed the uniform compacted structure of LGDM membrane as many cracks were formed in LGDM/GO, as shown in Fig. $2 \mathrm{~b}$ and $\mathrm{d}$.

The reduced modulus of membranes as illustrated in Fig. 4b, demonstrated similar trend with hardness when adding GO and was consistent with the study of $\mathrm{Wu}$ et al. in preparation of cellulose nanocrystal films using switchgrass and cotton, ${ }^{30}$ where the reduced modulus of fabricated films pursued similar
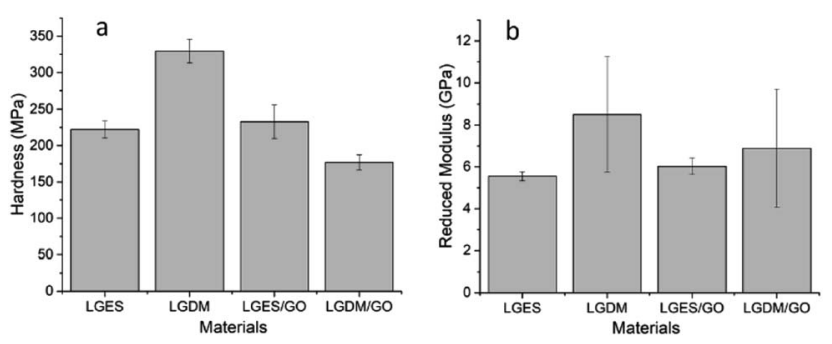

Fig. 4 Materials hardness (a) and reduced modulus (b) of 40 indents at a maximum load of $1 \mathrm{mN}$ load. LGES (lemongrass extracted solution) membrane, LGDM (lemongrass dissolved mixture) membrane, LGES/ GO (graphene oxide mixed with LGES (5/95 (w/w))) membrane and LGDM/GO (graphene oxide mixed with LGDM (5/95 (w/w))) membrane. Error bars indicated standard deviation. 
trend to the hardness of films. The large standard deviation of reduced modulus of LGDM and LGDM/GO membrane was probably due to the existence of LG particles and GO sheets as shown in Fig. $2 b$ and $d$.

Fig. 5 showed the SPM image and calculated average roughness $\left(R_{\mathrm{a}}\right)$ of fabricated membranes. Consistent with SEM images (Fig. 2), both LGES and LGES/GO membrane showed smoother surfaces compared to LGDM and LGDM/GO. LGDM/ GO membrane showed the highest roughness (ranged from $200 \mathrm{~nm}$ to $284.6 \mathrm{~nm}$ ) due to presence of LG particles and GO sheets. A large quantity of LG particles also resulted in higher roughness of LGDM membrane (183.4 $\pm 52.5 \mathrm{~nm})$ compared to LGES/GO membrane $(88.3 \pm 9.8 \mathrm{~nm})$. The roughness of membranes would be an advantage, as it may facilitate dye adsorption onto the membrane. This will be discussed further in the following section. The LGES membrane exhibited the lowest roughness $(81.7 \pm 24.1 \mathrm{~nm})$, which was consistent with the result of SEM images (Fig. 2). The addition of GO slightly increased the roughness of LGES membrane, which might be attributed to the homogeneous mixing and interaction between LGES solution and GO sheets.

\section{Thermogravimetric analysis}

The effect of temperature on weight loss of LGES, LGDM, LGES/ GO and LGDM/GO membranes along with LG snippets (LGSNP) for comparison purpose is demonstrated in Fig. 6. While the addition of GO slightly changed the thermal degradation of LGES and LGDM, three stages of thermal degradation can be seen for all samples. The first stage of thermal degradation occurring from room temperature to around $150{ }^{\circ} \mathrm{C}$ can be attributed to the loss of moisture and light volatile compounds of lemongrass. LGES showed the highest weight loss in this stage compared to the other four samples. This can be attributed to the higher moisture absorption of the membrane due to the purity of this membrane without any LG particles and GO nanosheets, as well as the higher amount of holes in the structure (as observed by SEM images) which induced more

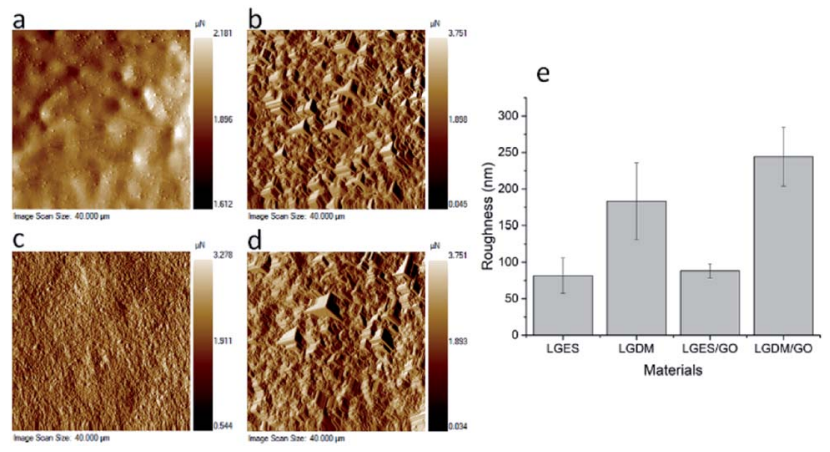

Fig. 5 SPM image (left) and Average Roughness $\left(R_{\mathrm{a}}\right)$ of materials (right): (a) LGES (lemongrass extracted solution) membrane; (b) LGDM (lemongrass dissolved mixture) membrane; (c) LGES/GO (graphene oxide mixed with LGES (5/95 (w/w))) membrane; (d) LGDM/GO (graphene oxide mixed with LGDM (5/95 (w/w))) membrane and (e) average roughness $\left(R_{\mathrm{a}}\right)$ of materials. Error bars indicated standard deviation.

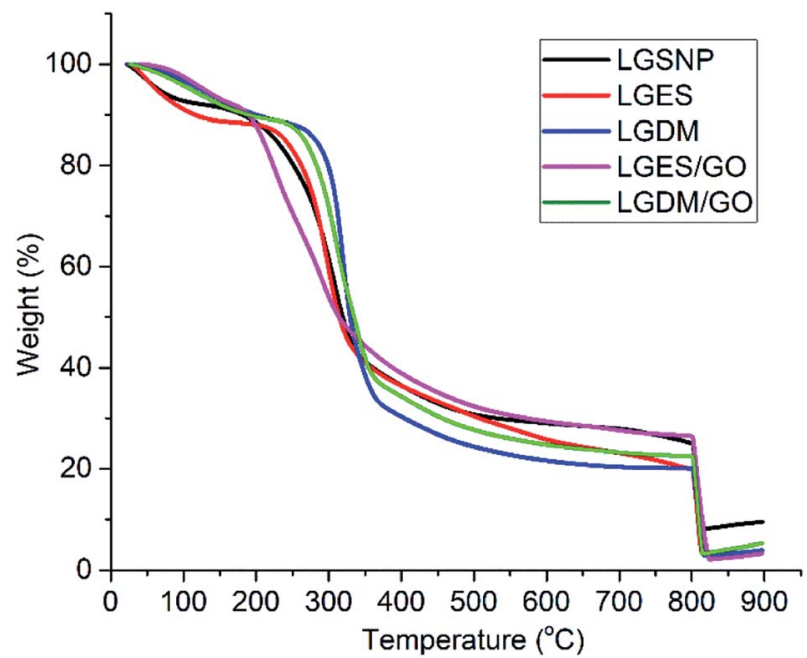

Fig. 6 Thermogravimetric analysis of LGSNP (lemongrass snippets), LGES (lemongrass extracted solution), LGDM (lemongrass dissolved mixture), LGES/GO (graphene oxide mixed with LGES (5/95 (w/w))) and LGDM/GO (graphene oxide mixed with LGDM (5/95 (w/w))) membranes.

moisture absorption. The weight loss rapidly decreased in the second stage which occurred from $150{ }^{\circ} \mathrm{C}$ to approximately $350^{\circ} \mathrm{C}$. This could be attributed to de-volatilization reactions in which most of the organic part of the LG was diminished as volatile matter. ${ }^{14}$ The third stage occurred between $350{ }^{\circ} \mathrm{C}$ and $800{ }^{\circ} \mathrm{C}$, where the weight loss decreased due to the continuous decomposition, however, LGDM showed faster degradation than the other four samples. This could be due to the existence of LG particles, which showed quicker decomposition. The remaining weight at $800{ }^{\circ} \mathrm{C}$ represents the char content of the samples: LGSNP (25.2\%), LGDM (20.1), LGES (20.0\%), LGES/GO (26.4\%) and LGDM/GO (22.5\%). A sharp weight drop occurred at $800{ }^{\circ} \mathrm{C}$ when gas switched from nitrogen to oxygen. The marked weight loss was attributed to the combustion of residual carbon. The final weight corresponded to the ash content of each sample. The remaining content of each sample was LGSNP (9.5\%), LGDM (3.9\%), LGES (3.4\%), LGES/GO (3.3\%) and LGDM/GO (5.3\%). The high remaining content of LGSNP at $900{ }^{\circ} \mathrm{C}$ might be due to the lignin which was not physically and chemically destroyed during sample preparation. It is worth mentioning that thermal degradation stages and ash content of LGDM membrane were found similar to that of milled LG particles reported by Lee et al. ${ }^{14}$ which further demonstrated the effect of LG particles on LGDM membrane properties.

\section{Dye adsorption analysis}

To analyse the dye adsorption of the fabricated membranes, methylene blue (MB) at three different initial concentrations of $15 \mathrm{mg} \mathrm{L}^{-1}, 100 \mathrm{mg} \mathrm{L}^{-1}$ and $400 \mathrm{mg} \mathrm{L}^{-1}$ was used. Fig. 7 shows $\mathrm{MB}$ adsorption behaviour of the prepared membranes within $24 \mathrm{~h}$ at room temperature. Table 2 lists the adsorption amount of $\mathrm{MB}$ at different initial concentrations after $24 \mathrm{~h}$ adsorption. All the prepared membranes showed the highest adsorption capacity at $400 \mathrm{mg} \mathrm{L}^{-1} \mathrm{MB}$ 

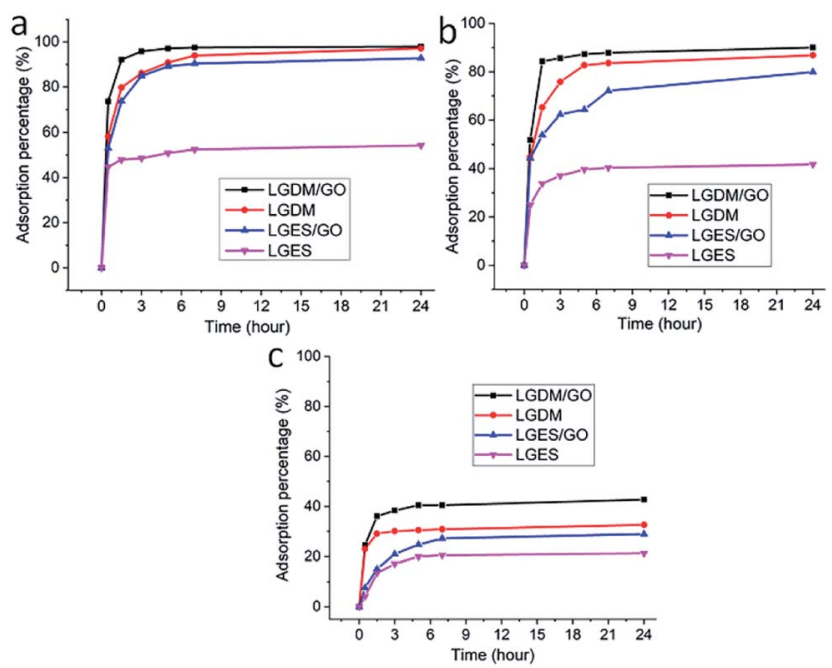

Fig. 7 Adsorption of different initial concentrations of methylene blue (MB) with LGES (lemongrass extracted solution), LGDM (lemongrass dissolved mixture), LGES/GO (graphene oxide mixed with LGES (5/95 $(w / w))$ ) and LGDM/GO (graphene oxide mixed with LGDM (5/95 (w/ w))) membranes, respectively, within $24 \mathrm{~h}$. (a) $15 \mathrm{mg} \mathrm{L}^{-1} \mathrm{MB}$, (b) $100 \mathrm{mg} \mathrm{L}^{-1} \mathrm{MB}$, (c) $400 \mathrm{mg} \mathrm{L}^{-1} \mathrm{MB}$.

concentration (Table 2). As shown in Fig. 7, at the initial 30 minute-mark, the LGDM/GO membrane showed the highest adsorption capacity at all the three MB concentrations, as well as the highest adsorption capacity of $68.4 \mathrm{mg} \mathrm{g}^{-1}$ at $400 \mathrm{mg} \mathrm{L}{ }^{-1} \mathrm{MB}$ concentration. This could be due to the combination of rough surface, presence of particles and GO layer in the LGDM/GO membrane (as shown in Fig. $2 \mathrm{~d}$ and $5 \mathrm{~d})$ which increased the surface area and binding sites of dye. At $15 \mathrm{mg} \mathrm{L}^{-1}$ concentration of $\mathrm{MB}$ and up to $7 \mathrm{~h}$, the LGDM membrane showed an identical adsorption behaviour to LGES/GO membrane. However, at both concentration of $15 \mathrm{mg} \mathrm{L}^{-1}$ and $100 \mathrm{mg} \mathrm{L}^{-1} \mathrm{MB}$ and after $7 \mathrm{~h}$, LGDM and LGDM/GO were almost identical and reached the plateau. The adsorption for both membranes after $24 \mathrm{~h}$, at $15 \mathrm{mg} \mathrm{L}^{-1}$ was almost $100 \%$ and at $100 \mathrm{mg} \mathrm{L}^{-1}$ of $\mathrm{MB}$ was greater than $80 \%$. The results are promising, as LGDM membrane showed higher $\mathrm{MB}$ adsorption (at $15 \mathrm{mg} \mathrm{L}^{-1}$ concentration, Table 2 ) at equilibrium $q_{\mathrm{e}}\left(5.64 \mathrm{mg} \mathrm{g}^{-1}\right)$ than the Daucus carrot leaves powder $\left(4.4 \mathrm{mg} \mathrm{g}^{-1}\right)$ under similar condition. $^{31}$ Even with different adsorbent dose and $\mathrm{MB}$ concentration, LGDM membrane also showed comparable MB adsorption at equilibrium with that of yellow passionfruit waste peel powder. ${ }^{32}$
While at higher concentration of MB (400 $\mathrm{mg} \mathrm{L}^{-1}$ ) LGDM/ GO showed higher adsorption compared to LGDM, the differences were around $10 \%$ and their initial adsorption was similar (25\%). LGES membrane showed the lowest MB adsorption among all membrane and at all three $\mathrm{MB}$ concentrations. Although the pores on the surface of LGES membrane (Fig. 2a) can provide more sites for dye adsorption, its compacted structure significantly limited the adsorption capacity. These findings indicated that the presence of lemongrass particles in LGDM membrane plays a major role in the dye removal and its behaviour in dye adsorption is comparable with membrane fabricated from GO with its large surface area which affects the diffusion of dyes onto the membrane. This further is discussed in next section; dye adsorption kinetics.

\section{Dye adsorption kinetics}

The adsorption kinetics of methylene blue $\left(15 \mathrm{mg} \mathrm{L}^{-1}\right)$ on LGDM/GO, LGDM, LGES/GO and LGES membranes were investigated using pseudo-first order, ${ }^{33}$ pseudo-second order $^{34}$ and intra-particle diffusion ${ }^{35}$ models and are plotted in Fig. 8.

The Lagergren pseudo-first order kinetic model $^{33}$ is expressed as the following equation:

$$
\ln \left(q_{\mathrm{e}}-q_{t}\right)=\ln q_{\mathrm{e}}-k_{1} t
$$

where $q_{\mathrm{e}}$ and $q_{t}$ are the amounts of $\mathrm{MB}\left(\mathrm{mg} \mathrm{g}^{-1}\right)$ adsorbed on membranes at equilibrium and time $t(\mathrm{~h})$, respectively, and $k_{1}$ is the rate constant of adsorption $\left(\mathrm{h}^{-1}\right)$. The values of $k_{1}$ and $q_{\mathrm{e}}{ }^{\text {cal }}$ calculated from the slopes $\left(-k_{1}\right)$ and intercepts $\left(\ln q_{\mathrm{e}}\right)$ of the linear plots (Fig. 8a) are listed in Table 3. Although all the membranes showed a high correlation coefficient, the experimental values of $q_{\mathrm{e}}\left(q_{\mathrm{e}}{ }^{\exp }\right.$ in Table 3) were higher than the $q_{\mathrm{e}}$ cal . Therefore the pseudo-first order model did not comply with the kinetic data.

The pseudo-second order kinetic model ${ }^{34}$ is expressed as the following equation:

$$
t / q_{t}=1 / k_{2} q_{\mathrm{e}}^{2}+t / q_{\mathrm{e}}
$$

where $k_{2}$ is the rate constant for the pseudo-second order adsorption process. $k_{2}$ and $q_{\mathrm{e}}{ }^{\text {cal }}$ (Table 3 ) were calculated from the intercepts $\left(1 / k_{2} q_{\mathrm{e}}{ }^{2}\right)$ and slopes $\left(1 / q_{\mathrm{e}}\right)$ of the linear plots Fig. $8 \mathrm{~b}$. The $q_{\mathrm{e}}{ }^{\text {cal }}$ values were similar to the $q_{\mathrm{e}}{ }^{\exp }$ on all the membranes and the correlation coefficient were all quite high at 0.999. These indicated that pseudo-second order adsorption is predominant for the fabricated membranes.

Table 2 Adsorption amount of MB of the fabricated membranes at different initial concentrations after $24 \mathrm{~h}$ adsorption

\begin{tabular}{llll}
\hline Absorbent membrane & $\begin{array}{l}\text { Adsorption amount } \\
\left(\mathrm{mg} \mathrm{g}^{-1}\right) \text { of } 15 \mathrm{mg} \mathrm{L}^{-1} \mathrm{MB}\end{array}$ & $\begin{array}{l}\text { Adsorption amount } \\
\left(\mathrm{mg} \mathrm{g}^{-1}\right) \text { of } 100 \mathrm{mg} \mathrm{L}^{-1} \mathrm{MB}\end{array}$ & $\begin{array}{l}\text { Adsorption amount } \\
\left(\mathrm{mg} \mathrm{g}^{-1}\right) \text { of } 400 \mathrm{mg} \mathrm{L}^{-1} \mathrm{MB}^{-}\end{array}$ \\
\hline LGDM/GO & 5.9 & 36.0 & 68.4 \\
LGDM & 5.8 & 34.7 & 52.2 \\
LGES/GO & 5.6 & 31.9 & 46.3 \\
LGES & 3.3 & 16.7 & 33.9
\end{tabular}



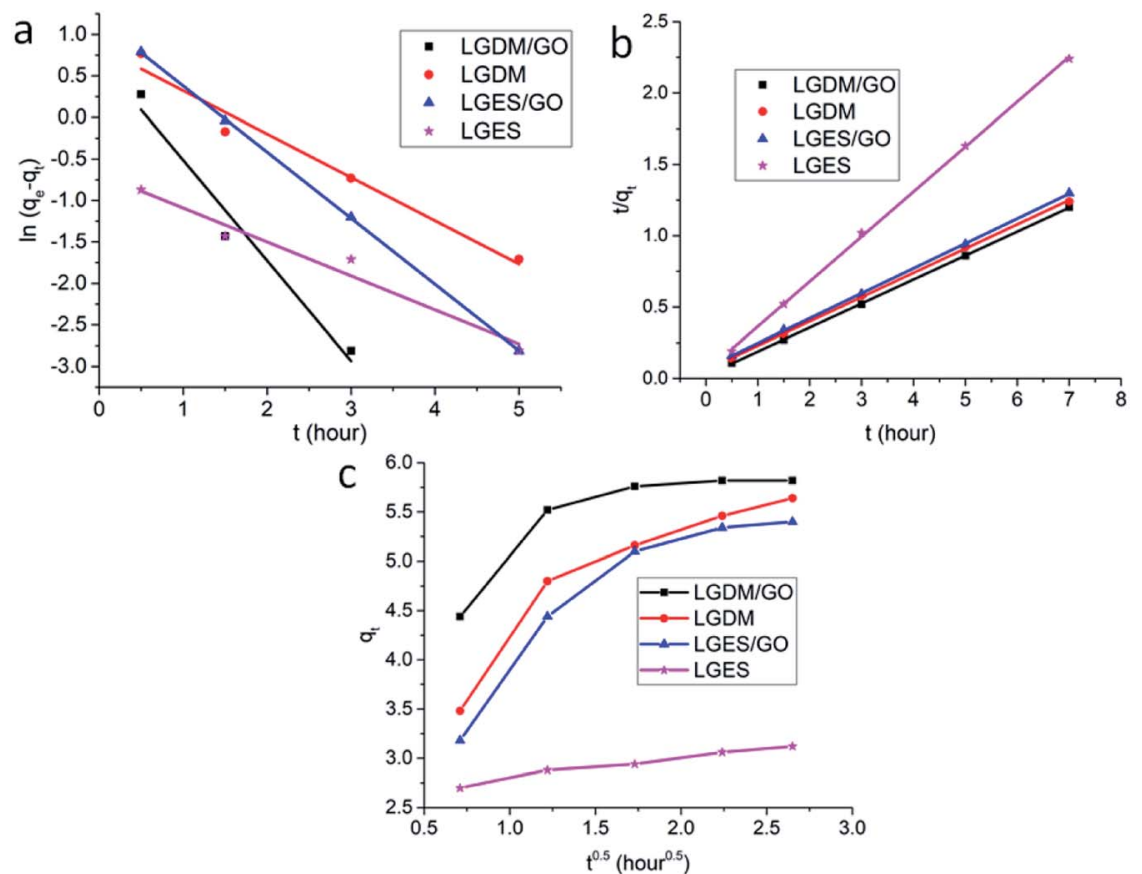

Fig. 8 Adsorption kinetics of methylene blue on lemongrass membranes: (a) pseudo-first order, (b) pseudo-second order, (c) intra-particle diffusion plot.

Intra-particle diffusion $^{35}$ model was also applied to investigate the role of diffusion in the membrane dye adsorption process, which is expressed as the following equation:

$$
q_{t}=k_{\mathrm{i}} t^{0.5}+C
$$

where $k_{\mathrm{i}}$ is the intra-particle diffusion constant. The intercept $(C)$ and slope $\left(k_{\mathrm{i}}\right)$ were calculated from the linear plots Fig. $8 \mathrm{c}$, and were listed in Table 3. Methylene blue adsorption on membranes included two steps: $\mathrm{MB}$ adsorption on the membrane surface (from $0.5^{0.5}$ to $1.5^{0.5}$ ) and $\mathrm{MB}$ diffusion into the adsorption sites on the membrane (from $1.5^{0.5}$ to $7^{0.5}$ ). The higher value of $\mathrm{C}$ demonstrated the higher surface adsorption of MB on the membrane. Therefore, LGDM/GO and LGDM membranes showed the highest surface adsorption of $\mathrm{MB}$ among all membranes. Rate of diffusion was also higher in LGDM than that of LGDM/GO. However, it is worth mentioning that the intra-particle diffusion model was better fitted for the LGDM rather than LGDM/GO $\left(R^{2}=0.991\right.$ and $R^{2}=0.787$, respectively). Therefore, it can be concluded that surface adsorption and intra-particle diffusion mechanism is more applicable to the LGDM compared to its composite with GO.

\section{Antibacterial activity}

Though the antibacterial activity of lemongrass essential (extracted) oil has been widely reported, ${ }^{36-38}$ there is no report on antibacterial property of membrane fabricated from lemongrass. Therefore, in this work, the antibacterial activity of lemongrass membranes was also evaluated to investigate if the fabrication process would retain the natural properties of lemongrass. The evaluation is shown by the inhibition zone (Fig. 9a and b, agar disc diffusion method), i.e., the clear zone surrounding the tested membrane where the growth of bacteria is inhibited due to the antibacterial property of membrane. Although there was no growth of bacteria on all the membranes, the inhibition zone was quite small which cannot clearly show the membrane antibacterial activity. To further investigate the antibacterial activity of prepared membranes during dye adsorption, the growth performance of bacteria in modified tryptone soya broth with and without a membrane (control) was monitored during $24 \mathrm{~h}$ (Fig. 9c). LGDM/GO membrane showed the

Table 3 Kinetic parameters for methylene blue adsorption on membranes

\begin{tabular}{|c|c|c|c|c|c|c|c|c|c|c|}
\hline Membrane & $q_{\mathrm{e}} \mathrm{exp}^{\exp }$ & \multicolumn{3}{|c|}{ Pseudo-first order } & \multicolumn{3}{|c|}{ Pseudo-second order } & \multicolumn{3}{|c|}{ Intra-particle diffusion } \\
\hline LGDM & 5.64 & 2.33 & 0.52 & 0.972 & 5.88 & 0.48 & 0.999 & 0.59 & 4.11 & 0.991 \\
\hline LGES/GO & 5.4 & 3.2 & 0.8 & 0.999 & 5.72 & 0.42 & 0.999 & 0.66 & 3.78 & 0.869 \\
\hline LGES & 3.12 & 0.506 & 0.41 & 0.968 & 3.17 & 1.93 & 0.999 & 0.18 & 2.66 & 0.983 \\
\hline
\end{tabular}



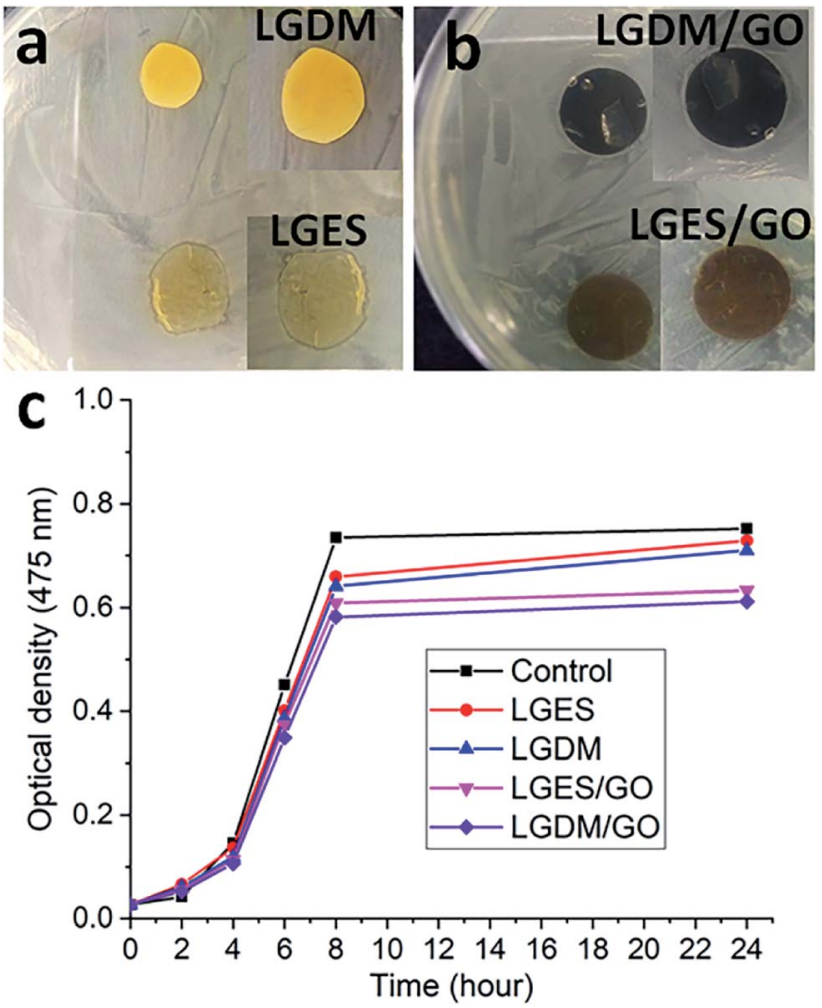

Fig. 9 Bacterial inhibition zone ( $a$ and b) and bacterial growth performance (c) of LGES (lemongrass extracted solution), LGDM (lemongrass dissolved mixture), LGES/GO (graphene oxide mixed with LGES (5/95 (w/w))) and LGDM/GO (graphene oxide mixed with LGDM $(5 / 95(\mathrm{w} / \mathrm{w})))$ membranes during $24 \mathrm{~h}$ of incubation against $E$. coli.

lowest optical density than the other membranes at each time point within $24 \mathrm{~h}$, which indicated its highest bacteria growth inhibition among the prepared membranes. This could be due to the full contact interactions between bacteria and membrane. The antibacterial property of GO and lemongrass works better in liquid phase using tryptone soya broth than on the solid agar plate. With the addition of GO, LGDM/GO and LGES/GO membrane had lower bacteria growth optical density than LGDM and LGES membrane, which means the incorporation of GO improves membrane antibacterial activity. Although the incorporation of GO can enhance antibacterial activity, ${ }^{39-41}$ the lemongrass membranes also showed antibacterial properties, and LGDM membrane demonstrated the comparable antibacterial activity with the LGDM/GO membrane within $7 \mathrm{~h}$ interaction. This further supports the hypothesis that the fabrication process would maintain the natural properties of lemongrass. Considering the low cost and abundance of lemongrass, the LGDM is more promising as dye adsorbent with antibacterial activity than the membrane with the addition of GO.

\section{Experimental}

\section{Materials}

Lemongrass was purchased from the local supermarket. Sodium hydroxide $(\mathrm{NaOH})$, urea and methylene blue (MB) were purchased from Sigma-Aldrich (Australia). Nylon membrane filters with pore size $0.45 \mu \mathrm{m}$ were from ProSciTech Pty Ltd (Australia).

\section{Preparation of lemongrass powder}

Lemongrass was rinsed with water and dried at $37^{\circ} \mathrm{C}$ for $60 \mathrm{~h}$. The dried lemongrass was first converted into snippets by the rotary cutter mill (Pulverisette 19, Fritsch $\mathrm{GmbH}$, Germany). The lemongrass snippets (LGSNP) then were mixed with deionized (DI) water $\left(0.1 \mathrm{~g} \mathrm{~mL}^{-1}\right)$ and milled into lemongrass slurry using Attritor milling (2S, Union Process, USA). The lemongrass powder was obtained by drying the above slurry with a mini spray dryer (B-290, Buchi Labortechnik AG, Switzerland).

\section{Synthesis of graphene oxide}

Graphene oxide (GO) dispersion was synthesized using the modified Hummers' method. ${ }^{42}$ First $1 \mathrm{~g}$ of expanded graphite was stirred in $200 \mathrm{~mL}$ sulfuric acid at $400 \mathrm{rpm}$ for $24 \mathrm{~h}$, and $10 \mathrm{~g}$ grounded $\mathrm{KMnO}_{4}$ powder was added into the mixture slowly and stirred for $24 \mathrm{~h}$. The mixture was put in an ice bath to decrease the temperature to $5{ }^{\circ} \mathrm{C}$. Then $200 \mathrm{~mL}$ DI water was injected into the mixture at different flow rates: the first $10 \mathrm{~mL}$ at $5 \mathrm{~mL} \mathrm{~h}^{-1}$, then $40 \mathrm{~mL}$ at $20-30 \mathrm{~mL} \mathrm{~h}^{-1}$ and the rest $150 \mathrm{~mL}$ at $50 \mathrm{~mL} \mathrm{~h}^{-1} .30 \% \mathrm{H}_{2} \mathrm{O}_{2}$ solution (no more than $30 \mathrm{~mL}$ ) was added into the mixture and stirred for another $30 \mathrm{~min}$ to consume the excessive $\mathrm{KMnO}_{4}$. Subsequently, $500 \mathrm{~mL}$ of $\mathrm{HCl}$ solution (water to $\mathrm{HCl}$ is $9: 1(\mathrm{v} / \mathrm{v}))$ was stirred with the mixture for $30 \mathrm{~min}$, followed by centrifuging at $6000 \mathrm{rpm}$ for $20 \mathrm{~min}$. The GO dispersion was repeatedly washed and centrifuged about 7 times until the $\mathrm{pH}$ reached 6 .

\section{Preparation of lemongrass membrane with and without graphene oxide}

Four different membranes were fabricated in this work as follows. Lemongrass powder $(1 \mathrm{~g})$ was dissolved in $100 \mathrm{~mL}$ of an aqueous mixture of $7 \% \mathrm{NaOH}$ and $12 \%$ urea at room temperature for 3 days. Then the mixture was dialyzed against DI water with a cellulose dialysis tube (molecular weight cut-off $=14000$ $\mathrm{kDa}$; Sigma Aldrich, Australia) at room temperature for 3 days. The dialysed solution containing lemongrass particles was used as the lemongrass-dissolved mixture (LGDM). Subsequently, the lemongrass-extracted solution (LGES) was obtained by centrifuging the LGDM, to remove undissolved lemongrass particles.

LGES solution was poured into a Petri dish and dried in a fume hood at room temperature to prepare LGES membrane. The membrane was dried further in the oven overnight at $60{ }^{\circ} \mathrm{C}$. LGDM solution mixture was filtrated through nylon membrane (0.45 $\mu \mathrm{m}$ pore, $47 \mathrm{~mm}$ diameter) using a vacuum filtration assembly, and the prepared LGDM membrane dried for $24 \mathrm{~h}$ at room temperature. GO water solution was added into LGES solution and ultra-sonicated for $4 \mathrm{~h}$, followed by vacuum filtration. After filtration, the LGES/GO (95 wt\% LGES : 5 wt\% GO) membrane was peeled off from the nylon membrane and dried for further testing. LGDM/GO (95 wt\% LGDM : $5 \mathrm{wt} \% \mathrm{GO}$ ) membrane was prepared using the same methods as LGES/GO membrane. Fig. 10 illustrates the preparation of the lemongrass 


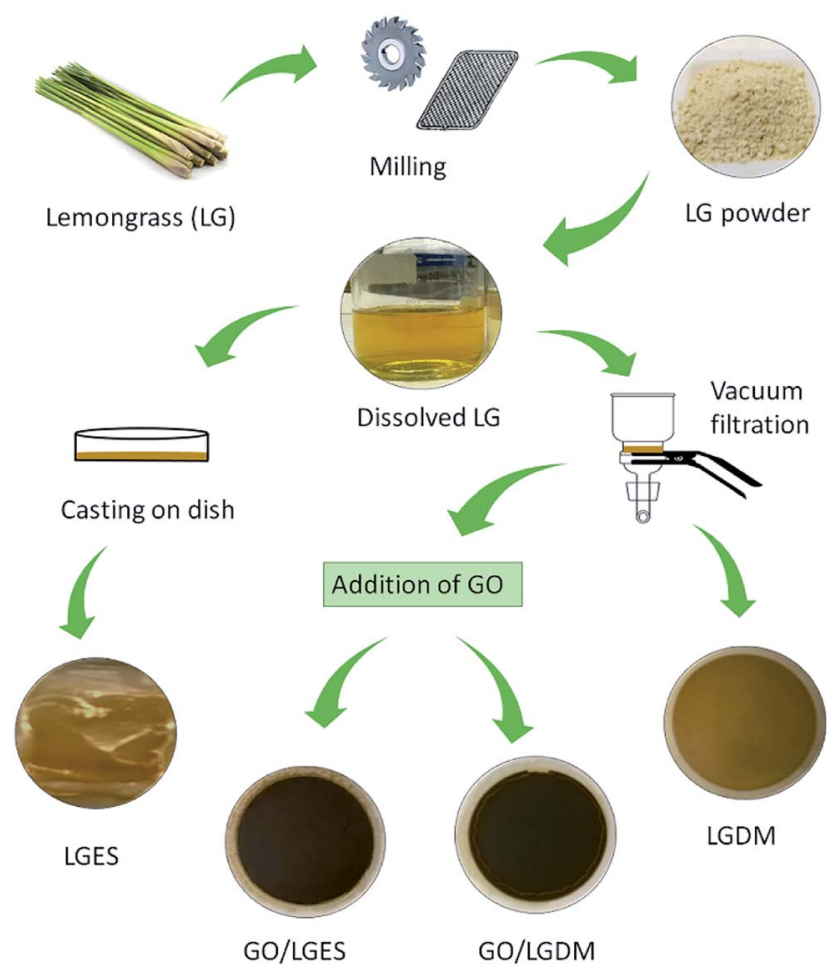

Fig. 10 Schematic fabrication process from lemongrass (LG) plant to membranes.

powder, lemongrass membrane as well as lemongrass/GO composite membranes.

\section{Characterization}

The particle size of lemongrass snippets and spray dried powder was measured using the Malvern Mastersizer 2000 (USA). The volume-based particle size test method was used to analyse the particle size: the volume medium diameter $d(0.5)$ represents that $50 \%$ particles are higher, and $50 \%$ particles are lower than the stated size. Additionally, $d(0.1)$ and $d(0.9)$ mean that $10 \%$ and $90 \%$ of the tested particles were smaller than the presented size. ${ }^{21}$ Error bars were neglected owing to the Mastersizer 2000 powder samples measurements having insignificant variation in $d(0.5)$ measurements.

The morphology of membranes was scanned using a scanning electron microscopy (SEM) (Zeiss Supra 55VP). Membranes were gold sputter-coated (Leica EM ACE600) and then imaged under the SEM with $5 \mathrm{kV}$ accelerating voltage. To obtain the cross-sectional image, membranes were submerged in liquid nitrogen for 3 minutes and the membranes were manually cross-sectioned using a clean, sharp razor blade, and the crosssections were gold sputter coated and imaged using SEM with 3 $\mathrm{kV}$ accelerating voltage.

The fine structure of the membranes was analysed using Fourier transform infrared spectroscopy (FTIR) and X-ray diffraction (XRD). The FTIR spectra of the membrane samples were obtained from Bruker Vertex 70 FTIR spectrometer with an ATR (attenuated total reflectance) mode, with a scan resolution of $4 \mathrm{~cm}^{-1}$ and 64 scans per sample in the range of $4000 \mathrm{~cm}^{-1}$
$500 \mathrm{~cm}^{-1}$. The spectral data were analysed (baseline correction) with OPUS 5.5 software.

The X-ray diffractogram (XRD) of all the samples was acquired by PANalytical X'Pert Power X-ray Diffraction instrument at $40 \mathrm{kV}$ and $30 \mathrm{~mA}$. The experiments were performed in the diffraction range from $6^{\circ}$ to $40^{\circ}$ at a $0.013^{\circ}$ step size with a speed of 150 seconds per step. The data then was extracted by Highscore Plus V4.6a software.

Thermal properties of LGSNP, LGES, LGDM, LGES/GO and LGDM/GO membranes were analysed using thermogravimetric analysis (TGA) which was conducted on TGA Q50 (USA). Samples $(5-10 \mathrm{mg})$ were heated from room temperature to $800{ }^{\circ} \mathrm{C}$ at a heating rate of $10{ }^{\circ} \mathrm{C} \min ^{-1}$ under a nitrogen atmosphere. The gas was changed to oxygen from $800{ }^{\circ} \mathrm{C}$ and heated to $900{ }^{\circ} \mathrm{C}$ at $10{ }^{\circ} \mathrm{C} \mathrm{min}^{-1}$.

Nano-indentation tests were conducted on all membrane samples with Hysitron "TI 950 Tribo-Indenter" to investigate hardness, reduced modulus and surface roughness. The equipment with a standard Berkovich probe was calibrated before each test.

The probe was forced onto the sample at $200 \mu \mathrm{N} \mathrm{s}^{-1}$ for 5 seconds and held at the peak load of $1000 \mu \mathrm{N}\left(P_{\max }\right)$ for 2 seconds, then unloaded at $200 \mu \mathrm{N} \mathrm{s}^{-1}$. Hardness $(H)$ was calculated based on the following formula: ${ }^{43}$

$$
H=\frac{P_{\max }}{A}
$$

where ' $P$ max ' is the maximum load $1000 \mu \mathrm{N}$ and ' $A$ ' is the probe contact area. 40 indentation tests were carried out on each membrane type, with $15 \mu \mathrm{m}$ distance between indents.

The membrane reduced modulus $E_{\mathrm{r}}$ was calculated following Oliver-Pharr model. ${ }^{44}$

$$
E_{\mathrm{r}}=\frac{S \sqrt{\pi}}{2 \sqrt{A}}
$$

where ' $S$ ' is the contact stiffness and ' $A$ ' is the probe contact area. ${ }^{44}$

Surface roughness $\left(R_{\mathrm{a}}\right)$ was measured using scanning probe microscopy (SPM). Seven spots were randomly chosen on each sample. The projected area of $1600 \mu \mathrm{m}^{2}$ was scanned at each spot with a probe speed of $16 \mu \mathrm{m} \mathrm{s}^{-1}$. Berkovich tip was used for SPM with an imaging load of $2 \mu \mathrm{N}$. Post scanning, 'Tribo view' software was used to remove sample tilt by 'background subtraction' routine and to calculate ' $R_{\mathrm{a}}$ '.

Three different initial methylene blue (MB) concentrations of $15 \mathrm{mg} \mathrm{L}^{-1}, 100 \mathrm{mg} \mathrm{L}^{-1}$ and $400 \mathrm{mg} \mathrm{L}^{-1}$ were prepared in DI water. For the dye adsorption test, $10 \mathrm{mg}$ of membranes were put in $4 \mathrm{~mL}$ of dye solution and shaken at a rate of $100 \mathrm{rpm}$ at ambient temperature. At time intervals of $0,0.5,1.5,3,5,7$ and $24 \mathrm{~h}$, the dye solution was respectively measured using a UV-Vis spectrophotometer (Cary 300, Agilent Technologies). The percentage of dye adsorption at each time interval was calculated using the following equation and based on the maximum absorption peak for MB (at $664 \mathrm{~nm}$ ):

$$
\text { Dye adsorption }(\%)=\frac{C_{0}-C_{t}}{C_{0}} \times 100 \%
$$


where $C_{0}$ is the dye adsorption at $0 \mathrm{~h}$, and $C_{t}$ is dye adsorption at each time interval.

The amount of dye adsorbed on membranes at equilibrium $q_{\mathrm{e}}\left(\mathrm{mg} \mathrm{g}^{-1}\right)$ was calculated using the following equation: ${ }^{31}$

$$
q_{\mathrm{e}}=\left(C_{0}-C_{\mathrm{e}}\right) V / M
$$

where $C_{\mathrm{e}}$ is the equilibrium concentration $\left(\mathrm{mg} \mathrm{L}^{-1}\right)$ of dye in solution, and $V$ is the solution volume (L) and $M$ is the mass of membrane (g).

The antibacterial property of membranes was tested using a disk diffusion method. Escherichia coli (E. coli; ATCC no. 11229) was used as test bacteria. E. coli strain was cultured in a sterilized glass bottle with modified tryptone soya broth (TSB) in a shaker incubator at $37{ }^{\circ} \mathrm{C}$ overnight. $100 \mu \mathrm{L}$ of inoculum containing approximately $10^{6} \mathrm{CFU} \mathrm{mL}{ }^{-1}$ was spread throughout the surface of tryptic soy agar plates and then circular discs for each type of membranes were placed on it and incubated in the incubator at $37{ }^{\circ} \mathrm{C}$ for $24 \mathrm{~h}$. Then the inhibition zones around the membranes were captured with a digital camera to illustrate the antibacterial property of membranes.

Bacteria growth performance in modified tryptone soya broth with and without membrane was monitored during $24 \mathrm{~h}$ to investigate the antibacterial activity of prepared membranes during dye adsorption. E. coli suspension $\left(10^{5} \mathrm{CFU} \mathrm{mL}^{-1}\right)$ was inoculated in $35 \mathrm{~mL}$ modified TSB with $50 \mathrm{mg}$ membrane. The control group was only $E$. coli suspension in $35 \mathrm{~mL}$ modified TSB. These bottles were then stored in a shaker incubator (at $110 \mathrm{rpm}$ ) at $37{ }^{\circ} \mathrm{C}$ for $24 \mathrm{~h}$. E. coli growth performance was investigated by measuring the optical density at $475 \mathrm{~nm}$ at 0,2 , 4, 6, 8 and 24 h.

\section{Conclusions}

This paper demonstrates a facile technique to fabricate membranes from lemongrass with antibacterial property for dye removal. The lemongrass dissolved mixture membrane (LGDM), with the highest hardness and reduced modulus, demonstrated an excellent dye adsorption capacity which is comparable to its composite with graphene oxide (LGDM/GO). This was due to the rough structure of LGDM with the existence of partially dissolved lemongrass particles. With the addition of graphene oxide, composite membrane showed layered structure. This layered structure induced the decrease in hardness and reduced modulus of lemongrass dissolved mixture/graphene oxide (LGDM/GO) membrane compared with lemongrass dissolved mixture membrane (LGDM). The methylene blue adsorption on membranes fitted well with pseudosecond order and intra-particle diffusion models, where it showed that lemongrass dissolved mixture membrane (LGDM) followed both the surface adsorption and intra-particle diffusion mechanism. The antibacterial experiments also supported the hypothesis that the fabrication process would maintain the natural properties of lemongrass. In a combination with the facile fabrication technology, improved mechanical properties, good dye adsorption, antibacterial properties and easy adsorbent separation after dye adsorption, the lemongrass dissolved mixture membrane could be a promising candidate for water filtration.

\section{Conflicts of interest}

There are no conflicts to declare.

\section{Acknowledgements}

The current study was carried out with the support of the Deakin Advanced Characterization Facility.

\section{References}

1 C. J. Ogugbue and T. Sawidis, Biotechnol. Res. Int., 2011, 2011, 967925.

2 H. B. Mansour, I. Houas, F. Montassar, K. Ghedira, D. Barillier, R. Mosrati, et al., Environ. Sci. Pollut. Res., 2012, 19(7), 2634-2643.

3 R. O. A. de Lima, A. P. Bazo, D. M. F. Salvadori, C. M. Rech, D. de Palma Oliveira and G. de Aragão Umbuzeiro, Mutat. Res., Genet. Toxicol. Environ. Mutagen., 2007, 626(1-2), 53-60.

4 B. Khemila, B. Merzouk, A. Chouder, R. Zidelkhir, J.-P. Leclerc and F. Lapicque, Sustainable Chem. Pharm., 2018, 7, 27-35.

5 A. Ahmad, S. H. Mohd-Setapar, C. S. Chuong, A. Khatoon, W. A. Wani, R. Kumar, et al., RSC Adv., 2015, 5(39), 3080130818.

6 M. Visa and A.-M. Chelaru, Appl. Surf. Sci., 2014, 303, 14-22.

7 A. Salama, J. Colloid Interface Sci., 2017, 487, 348-353.

8 U. Habiba, T. A. Siddique, T. C. Joo, A. Salleh, B. C. Ang and A. M. Afifi, Carbohydr. Polym., 2017, 157, 1568-1576.

9 L. Melo, T. J. E. Bott and f science, Exp. Therm. Fluid Sci., 1997, 14(4), 375-381.

10 F. Liu, S. Chung, G. Oh and T. S. Seo, ACS Appl. Mater. Interfaces, 2012, 4(2), 922-927.

11 O. Akhavan and E. Ghaderi, ACS Nano, 2010, 4(10), 57315736.

12 J. A. González, M. E. Villanueva, L. L. Piehl and G. J. Copello, Chem. Eng. J., 2015, 280, 41-48.

13 N. A. Travlou, G. Z. Kyzas, N. K. Lazaridis and E. A. Deliyanni, Chem. Eng. J., 2013, 217, 256-265.

14 L. Lee, X. Lee, P. Chia, K. Tan and S. Gan, J. Taiwan Inst. Chem. Eng., 2014, 45(4), 1764-1772.

15 G. Annadurai, R. S. Juang and D. J. Lee, J. Hazard. Mater., 2002, 92(3), 263-274.

16 R. Batmaz, N. Mohammed, M. Zaman, G. Minhas, R. M. Berry and K. C. Tam, Cellulose, 2014, 21(3), 1655-1665.

17 A. N. M. A. Haque, R. Remadevi and M. Naebe, Cellulose, 2018, 25(10), 1-23.

18 C. E. Ekpenyong, E. Akpan and A. Nyoh, Chin. J. Nat. Med., 2015, 13(5), 321-337.

19 K. Lal, R. Yadav, R. Kaur, D. Bundela, M. I. Khan, M. Chaudhary, et al., Ind. Crops Prod., 2013, 45, 270-278.

20 H. Singh and T. B. Dawa, Carbon Letters (Carbon Lett)., 2014, 15(2), 105-112. 
21 M. A. Al Faruque, R. Remadevi, X. Wang and M. Naebe, J. Powder Technol., 2019, 342, 848-855.

22 N. Sun, M. Rahman, Y. Qin, M. L. Maxim, H. Rodríguez and R. D. Rogers, Green Chem., 2009, 11(5), 646-655.

23 N. D. Luong, N. Pahimanolis, U. Hippi, J. T. Korhonen, J. Ruokolainen, L.-S. Johansson, et al., J. Mater. Chem., 2011, 21(36), 13991-13998.

24 C. Shao, Z. Zhu, C. Su, S. Yang and Q. Yuan, Materials, 2018, 11(9), 1727.

25 X. Chen, S. Zhou, L. Zhang, T. You and F. J. M. Xu, Materials (Basel), 2016, 9(7), 582.

26 Y. Hao, Y. Cui, J. Peng, N. Zhao, S. Li and M. Zhai, Carbohydr. Polym., 2019, 208, 269-275.

27 S. Y. Oh, D. I. Yoo, Y. Shin, H. C. Kim, H. Y. Kim, Y. S. Chung, et al., Carbohydr. Res., 2005, 340(15), 2376-2391.

28 D. Han, L. Yan, W. Chen, W. Li and P. Bangal, Carbohydr. Polym., 2011, 83(2), 966-972.

29 W. Ouyang, J. Sun, J. Memon, C. Wang, J. Geng and Y. Huang, Carbon, 2013, 62, 501-509.

30 Q. Wu, Y. Meng, K. Concha, S. Wang, Y. Li, L. Ma, et al., Ind. Crops Prod., 2013, 48, 28-35.

31 A. K. Kushwaha, N. Gupta and M. Chattopadhyaya, J. Saudi Chem. Soc., 2014, 18(3), 200-207.

32 F. A. Pavan, E. C. Lima, S. L. Dias and A. C. Mazzocato, J. Hazard. Mater., 2008, 150(3), 703-712.
33 S. Lagergren, Sven Vetenskapsakad Handingarl, 1898, 24, 139.

34 Y.-S. Ho and G. McKay, Process Biochem., 1999, 34(5), 451465.

35 W. J. Weber and J. C. Morris, J. Sanit. Eng. Div., 1963, 89(2), 31-60.

36 M. Maizura, A. Fazilah, M. Norziah and A. Karim, J. Food Sci., 2007, 72(6), C324-C330.

37 G. O. Onawunmi, W.-A. Yisak and E. Ogunlana, J. Ethnopharmacol., 1984, 12(3), 279-286.

38 G. Shah, R. Shri, V. Panchal, N. Sharma, B. Singh and A. Mann, J. Adv. Pharm. Technol. Res., 2011, 2(1), 3.

39 N. Cai, H. Zeng, J. Fu, V. Chan, M. Chen, H. Li, et al., J. Appl. Polym. Sci., 2018, 135(19), 46238.

40 O. Akhavan and E. Ghaderi, ACS Nano, 2010, 4(10), 57315736.

41 W. Hu, C. Peng, W. Luo, M. Lv, X. Li, D. Li, et al., ACS Nano, 2010, 4(7), 4317-4323.

42 D. C. Marcano, D. V. Kosynkin, J. M. Berlin, A. Sinitskii, Z. Sun, A. Slesarev, et al., ACS Nano, 2010, 4(8), 4806-4814.

43 W. C. Oliver and G. M. Pharr, J. Mater. Res., 2004, 19(1), 3-20.

44 W. C. Oliver and G. M. Pharr, J. Mater. Res., 1992, 7(6), 15641583. 